\title{
High-Efficiency Power Supply for Resistive Loads with Sinusoidal Input Current
}

\author{
L. Rossetto*, L. Malesani*, G. Spiazzi** \\ J. A. Pomilio***, M. Monacchi**** \\ *Department of Electrical Engineering, **Department of Electronics and Informatics \\ University of Padova, Via Gradenigo 6/a, 35131 Padova - ITALY \\ Phone: +39-49-828.7500 Fax: +39-49-828.7599/7699 \\ ***Dept. de Sistemas e Controle de Energia \\ UNICAMP, c.p. 6101, 13.081 Campinas - BRASIL \\ ****Whirlpool Europe
}

Viale G. Borghi, 27, 21025 Comerio (Varese) - ITALY

\begin{abstract}
A high-quality rectifier for supplying resistive loads is presented. It features high power factor, low input current ripple and high efficiency. Device stresses are the same as for a buck converter, and input current is continuous.

A suitable auxiliary network provides zero voltage switching for both power switch and diode.

The ripple steering technique was applied in order to reduce the input current ripple.

The converter, suitable for heating and lighting applications, was analyzed and experimentally tested on a $1 \mathrm{~kW}$ prototype.
\end{abstract}

\section{INTRODUCTION}

The market for household appliances is becoming an important application area for power electronics. In fact, as compared to electromechanical devices, electronic power supplies offer superior performances at a similar cost. One of the main application area regards supplies for resistive loads in lighting and heating applications where futures like continuous power regulation, accuracy irrespective of line voltage variations, protection against short-circuits and open-circuits, power limitation etc. are becoming mandatory requirements.

On the other hand, electronic power supplies must be considered carefully as regards efficiency, reliability and harmonic distortion. From these points of view, topologies which provide low input current ripple are preferred, in order to reduce the size of the input filter. EMI problems are also crucial, calling for soft-switching techniques. Other common requirements for resistive loads are: direct supply from the utility line; high power factor; output power regulation from a few percent to $100 \%$ of rated power; high power density; limited power loss.

The care reserved to the utility line interface comes from the attempt to meet standard regulations and recommendations (like IEC 1000-3-2) while the severe environmental conditions, in terms of available space and ambient temperature, in which these power supplies can work call for high power density and efficiency.

In the following a simple high-quality rectifier for supplying resistive loads is presented and briefly analyzed in its several operating modes. The circuit features: high power factor, zero-voltage switching, obtained by using a suitable auxiliary network and low input current ripple, achieved by exploiting the ripple steering phenomenon.

Experimental results of a prototype are reported, showing actual converter performances.

\section{BASIC CONVERTER SCHEME}

The proposed converter scheme, shown in Fig. 1, is a step-down topology derived from the Cuk cell by a cyclic rotation of the components[1-3]. Due to the presence of the input inductor $\mathrm{L}_{1}$, it draws a current with a much lower frequency content as compared to a standard buck converter. Moreover, this topology is suitable for the application of the ripple steering concept which further reduces the input current high-frequency ripple.

Due to the presence of two inductors and the diode bridge rectifier, more operation modes are possible. As reported in [3], besides the usual Continuous Conduction Mode (CCM) and Discontinuous Conduction Mode (DCM), the converter can work in Discontinuous Input Current Mode (DICM) in which only the input diodes stop conducting during the switch off-interval, and in Discontinuous Input and Output Current Mode (DIOCM), characterized by discontinuous currents in both inductors. Both these latter operation modes lead to different fundamental relations as compared to the buck converter; however, as suggested in [3], they are not recommended since produce a higher input current ripple and, above all, a 
higher switch voltage stress at light load, which limits the load range the converter can work with.

In the next section we will briefly review the converter behavior only for CCM and DCM operation modes; for a more comprehensive treatment the reader is suggested to consult [3].

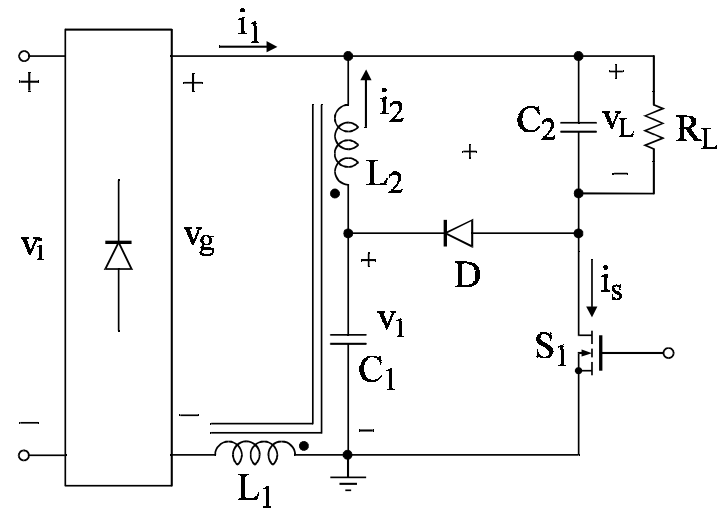

Fig.1 - Basic converter scheme

\section{REVIEW OF OPERATION MODES: CCM AND DCM}

In the following analysis we will consider two separate inductors $\mathrm{L}_{1}$ and $\mathrm{L}_{2}$; the effects of the coupling will be taken into account later. For the application we are dealing with, the instantaneous output voltage, as well as the output power, is allowed to vary during the line cycle, since the goal is to control the average power supplied to the load. Thus, the circuit does not include large energy storage devices.

Assuming a switching frequency much higher than the line frequency, we can write:

$\mathrm{v}_{\mathrm{g}}(\theta)=\mathrm{V}_{\mathrm{i}} \cdot|\sin (\theta)|$

$\overline{\mathrm{V}}_{\mathrm{L}}(\theta)=\mathrm{V}_{\mathrm{L}} \cdot|\sin (\theta)|, \quad \theta=\omega_{\mathrm{i}} \mathrm{t}$

where $\omega_{\mathrm{i}}$ is the line angular frequency. Since all reactive elements of the converter are designed to handle energy at the switching frequency, from the power balance in a switching cycle, assuming unity converter efficiency, we can write:

$\mathrm{v}_{\mathrm{g}}(\theta) \cdot \overline{\mathrm{i}}_{1}(\theta)=\frac{\mathrm{v}_{\mathrm{L}}^{2}(\theta)}{\mathrm{R}_{\mathrm{L}}} \Rightarrow \overline{\mathrm{i}}_{1}(\theta)=\frac{\mathrm{M}^{2}}{\mathrm{R}_{\mathrm{L}}} \mathrm{V}_{\mathrm{i}}|\sin (\theta)|$

where the overbar means averaged quantities in a switching period and $\mathrm{M}=\frac{\overline{\mathrm{v}}_{\mathrm{L}}(\theta)}{\mathrm{v}_{\mathrm{g}}(\theta)}=\frac{\mathrm{V}_{\mathrm{L}}}{\mathrm{V}_{\mathrm{i}}}$ is the voltage conversion ratio. This relation reveals that a high power factor is achieved for constant duty-cycle and switching frequency.

The relations and converter waveforms given hereafter are valid provided that the high-frequency voltage ripple across capacitors $\mathrm{C}_{1}$ and $\mathrm{C}_{2}$ is neglected.

1) CCM operation. Looking at Fig. 2 a which reports the main converter waveforms during a switching period for the case of CCM operation, both inductor currents are continuous and the converter equations are the same of the buck topology. Both switch and freewheeling diode carry the sum of the two inductor currents during the on- and off-intervals respectively.

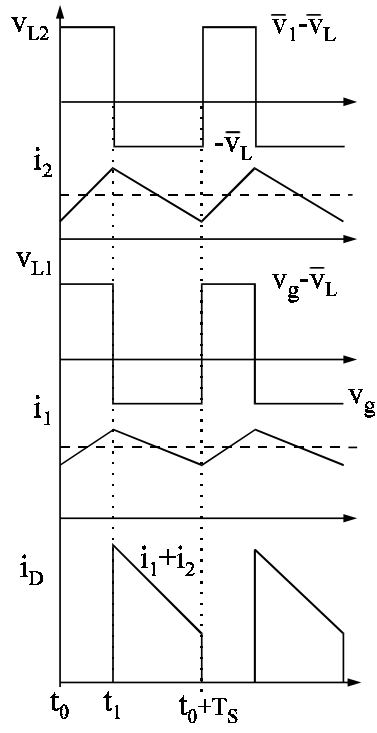

a)

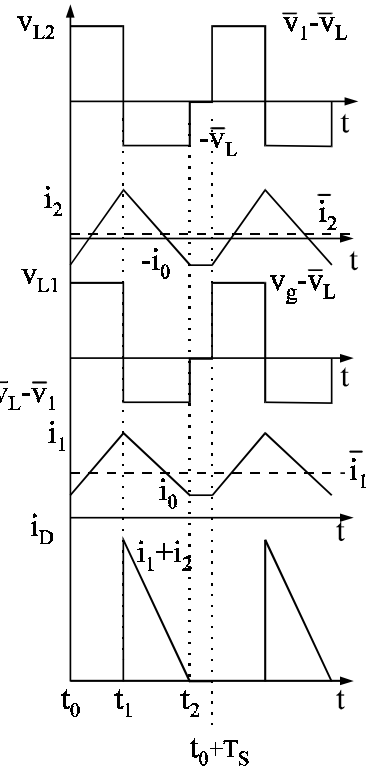

b)
Fig.2 - Main converter waveforms in a switching period. a) CCM operation, b) DCM operation

The volt-second balance applied to inductors $\mathrm{L}_{1}$ and $\mathrm{L}_{2}$ gives:

$$
\begin{aligned}
& \overline{\mathrm{v}}_{1}(\theta)=\mathrm{v}_{\mathrm{g}}(\theta) \\
& \mathrm{M}=\frac{\overline{\mathrm{v}}_{\mathrm{L}}(\theta)}{\mathrm{v}_{\mathrm{g}}(\theta)}=\frac{\mathrm{V}_{\mathrm{L}}}{\mathrm{V}_{\mathrm{i}}}=\mathrm{d}
\end{aligned}
$$

where $d$ is the duty-cycle $\left(\mathrm{dT}_{\mathrm{S}}=\mathrm{t}_{0} \div \mathrm{t}_{1}\right)$. It is important to note that, due to the presence of the input diode bridge rectifier, current $i_{1}$ must always be greater than zero, leading to the following constraint on inductor $\mathrm{L}_{1}$ :

$\mathrm{L}_{1}>\frac{\mathrm{R}_{\mathrm{L}}}{2 \mathrm{f}_{\mathrm{S}}} \cdot\left(\frac{1-\mathrm{M}}{\mathrm{M}}\right)$

where $f_{S}$ is the switching frequency.

From Fig. 2a it is also possible to calculate the peak current in both switch and freewheeling diode:

$\mathrm{i}_{\mathrm{S} \text {, peak }}=\mathrm{i}_{\mathrm{D} \text {, peak }}=\frac{\mathrm{V}_{\mathrm{i}}}{\mathrm{R}_{\mathrm{L}}} \cdot \mathrm{M} \cdot\left(1+\frac{1-\mathrm{M}}{\mathrm{k}}\right)$

$\mathrm{k}=\frac{2 \mathrm{~L}_{\mathrm{e}} \mathrm{f}_{\mathrm{S}}}{\mathrm{R}_{\mathrm{L}}}, \quad \mathrm{L}_{\mathrm{e}}=\frac{\mathrm{L}_{1} \cdot \mathrm{L}_{2}}{\mathrm{~L}_{1}+\mathrm{L}_{2}}$

1) DCM operation. With this operation mode the freewheeling diode current is discontinuous, leading to the typical waveforms of Fig. 2b. The main difference respect to the buck converter is that the input current remains continuous in spite of the zeroing of the diode current which, in fact, is the sum of the two's.

From the analysis of the waveforms of Fig. $2 b$ we find that the first of (3) is still valid while the voltage conversion ratio results: 


$$
\mathrm{M}=\frac{2}{1+\sqrt{1+\frac{4 \mathrm{k}}{\mathrm{d}^{2}}}}
$$

which is the same relation of a buck converter having an inductance equal to $\mathrm{L}_{\mathrm{e}}$.

Note that for the application we are dealing with, parameter $\mathrm{k}$ is constant because the load is assigned, while $\mathrm{M}$ must vary from zero to one in order to regulate the power delivered to the load. Thus, the value $\mathrm{M}_{1}$ corresponding to the boundary between DCM and CCM operation is:

$\mathrm{M}_{1}=1-\mathrm{k}$

The condition which ensures a current $i_{1}$ greater than zero is given by the inequality:

$\frac{\mathrm{L}_{1}}{\mathrm{~L}_{2}}>\frac{1-\mathrm{M}}{\mathrm{M}}$

The switch and diode current stress is given by:

$\mathrm{i}_{\mathrm{S} \text {,peak }}=\mathrm{i}_{\mathrm{D} \text {,peak }}=\frac{2 \mathrm{~V}_{\mathrm{i}}}{\mathrm{R}_{\mathrm{L}}} \cdot \mathrm{M} \cdot \sqrt{\frac{1-\mathrm{M}}{\mathrm{k}}}$

\section{POWER STAGE DESIGN CRITERIA}

As explained before it is convenient to design the converter for CCM and DCM operation modes only, in order to limit current and voltage stresses. While CCM operation, compared to DCM, ensures the lowest current ripples and thus the minimum current stresses and minimum conduction losses, it has the drawback of having higher turn on losses as well as EMI due to hard recovery of the freewheeling diode. Moreover, it requires high inductance values.

Taking into account the above considerations, it seems reasonable to design the converter in such a way that its operation mode changes from CCM to DCM when the voltage conversion ratio decreases from one to zero.

\section{1) Converter Specification:}

Peak Input voltage: $\mathrm{V}_{\mathrm{i}}$

Load Resistance: .

Switching Frequency:

\section{$\mathrm{R}_{\mathrm{L}}$} $f_{S}$

2) Switch and Diode Current Stress. As stated above, at maximum output voltage $(\mathrm{M}=1)$ the converter operates in CCM. Calling $\mathrm{M}_{1}$ the value of the voltage conversion ratio in correspondence of which the converter enters the DCM region, the maximum normalized switch and diode current stress results (from (5) and (9)):

$$
\mathrm{i}_{\text {SN,peak }}=\frac{\mathrm{i}_{\text {S.peak }} \cdot \mathrm{R}_{\mathrm{L}}}{\mathrm{V}_{\mathrm{i}}}=\left\{\begin{array}{lll}
\frac{4}{3 \sqrt{3}} \frac{1}{\sqrt{k}} & \text { if } & \mathrm{k}<\frac{1}{3} \\
\frac{(1+\mathrm{k})^{2}}{4 \mathrm{k}} & \text { if } & \mathrm{k}>\frac{1}{3}
\end{array}\right.
$$

in which the relation $\mathrm{k}=1-\mathrm{M}_{1}$ was used (see (7)).

Fig. 3 reports the variation of the normalized current stress as a function of parameter $\mathrm{k}$. This plot can be useful to chose the value of $\mathrm{k}$ (and thus of $\mathrm{M}_{1}$ ) making a trade off between the maximum allowed current stress, which calls for a high $\mathrm{k}$ value, and the inductor size, as it will result from the following analysis (in fact, high $\mathrm{k}$ means a wider range of CCM operation).

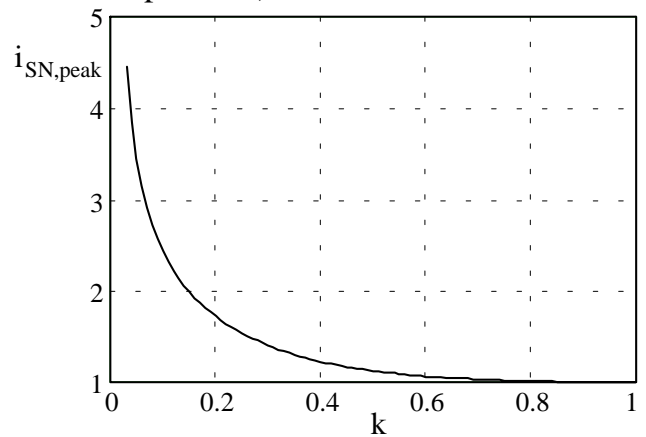

Fig. 3 - Normalized switch and diode current stress as a function of parameter $\mathrm{k}$

3) Inductances $L_{1}$ and $L_{2}$. From (7) the value of parameter $\mathrm{k}$ is found as $\mathrm{k}=1-\mathrm{M}_{1}$ and from its definition the value of equivalent inductance $\mathrm{L}_{\mathrm{e}}$ is obtained as:

$$
\mathrm{L}_{\mathrm{e}}=\frac{\mathrm{L}_{1} \mathrm{~L}_{2}}{\mathrm{~L}_{1}+\mathrm{L}_{2}}=\frac{\mathrm{R}_{\mathrm{L}}}{2 \mathrm{f}_{\mathrm{S}}} \cdot\left(1-\mathrm{M}_{1}\right)
$$

A second constraint on the two inductors is given by inequality (8):

$$
\frac{\mathrm{L}_{1}}{\mathrm{~L}_{2}}>\frac{1-\mathrm{M}_{2}}{\mathrm{M}_{2}}
$$

where $\mathrm{M}_{2}$ is the value of the conversion ratio in correspondence of which current $i_{1}$ zeroes every switching cycle. This value must be chosen suitably lower than $\mathrm{M}_{1}$, in order to reduce the input current ripple, thus reducing input filter requirements. From (11) and (12), the values of inductances $L_{1}$ and $L_{2}$ are derived as follows:

$\mathrm{L}_{1}=\frac{\mathrm{R}_{\mathrm{L}}}{2 \mathrm{f}_{\mathrm{S}}} \cdot\left(\frac{1-\mathrm{M}_{1}}{\mathrm{M}_{2}}\right)$

$\mathrm{L}_{2}=\frac{\mathrm{R}_{\mathrm{L}}}{2 \mathrm{f}_{\mathrm{S}}} \cdot\left(\frac{1-\mathrm{M}_{1}}{1-\mathrm{M}_{2}}\right)$

Note that the value of $L_{1}$ obtained from (13.a) automatically satisfies constraint (4) which, as demonstrated in [3], ensures a transfer from CCM to DCM operation without entering the DICM region.

4) Capacitance $C_{1}$ and $C_{2}$. The values of the two capacitances is chosen on the basis of the desired voltage ripples. For a detailed derivation of these ripples see reference [3].

\section{RIPPLE STEERING CONCEPT}

The ripple-steering phenomenon was originally investigated in Cuk converters [5], but it can effectively be applied to all converter topologies in which two or more inductors are fed by similar (scaled) voltage waveforms. And this is exactly the case for the proposed step-down topology (see Fig. 2a and 2b), since the first of (3) remains 
valid both for CCM and DCM operations. Thus we can draw the equivalent circuit model shown in Fig. 4.

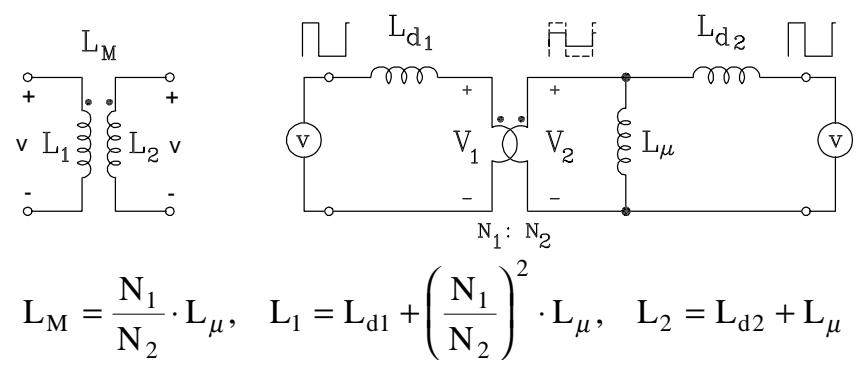

Fig. 4 - Coupled-inductor equivalent circuit

As stated above, due to converter operation, the same voltage $\mathrm{v}$ is applied to both windings. Accordingly, zero ripple condition of primary current is easily derived by observing that secondary leakage inductance $\mathrm{L}_{\mathrm{d} 2}$ and magnetizing inductance $\mathrm{L}_{\mu}$ form an inductive divider which scales the voltage applied to the secondary winding without altering its shape (voltage $V_{2}$ in Fig. 4). If turn ratio $\mathrm{N}_{1} / \mathrm{N}_{2}$ is chosen to step-up the voltage $V_{2}$ to the original value $v$, zero current ripple on the primary side is obtained. Thus, the zero ripple condition is [6]:

$\frac{\mathrm{N}_{2}}{\mathrm{~N}_{1}}=\frac{\mathrm{L}_{\mu}}{\mathrm{L}_{\mu}+\mathrm{L}_{\mathrm{d} 2}}=\mathrm{k}_{\mathrm{r}}$

where $\mathrm{k}_{\mathrm{r}}$ is defined as secondary coupling coefficient. The input current ripple does not simply disappear, but it is "steered" into the other winding.

We can obtain the same result starting from the mutual inductor equations: assuming the same voltage applied on both windings, we can derive the rate of change of the currents in the two windings:

$\frac{\mathrm{di}_{1}}{\mathrm{dt}}=\frac{\mathrm{v}}{\mathrm{L}_{\text {leq }}}, \quad \frac{\mathrm{di}_{2}}{\mathrm{dt}}=\frac{\mathrm{v}}{\mathrm{L}_{2 \mathrm{eq}}}$

where,

$$
\mathrm{L}_{\text {leq }}=\mathrm{L}_{1} \cdot \frac{1-\frac{\mathrm{L}_{\mathrm{M}}^{2}}{\mathrm{~L}_{1} \mathrm{~L}_{2}}}{1-\frac{\mathrm{L}_{\mathrm{M}}}{\mathrm{L}_{2}}}, \quad \mathrm{~L}_{2 \mathrm{eq}}=\mathrm{L}_{2} \cdot \frac{1-\frac{\mathrm{L}_{\mathrm{M}}^{2}}{\mathrm{~L}_{1} \mathrm{~L}_{2}}}{1-\frac{\mathrm{L}_{\mathrm{M}}}{\mathrm{L}_{1}}}
$$

From these expressions, it is seen that, to obtain zero ripple current in the input winding, the equivalent input inductance $\mathrm{L}_{1 \text { eq }}$ must be infinity, which is accomplished by selecting $\mathrm{L}_{2}=\mathrm{L}_{\mathrm{M}}$. With this choice, we obtain also $\mathrm{L}_{2 \mathrm{eq}}=\mathrm{L}_{2}$. Using the relations reported in Fig. 4 , it is easily verified that this zero ripple condition is equivalent to the previous one (14).

It is important to observe that the actual coupled inductor behavior deviates from the ideal one mainly for the following two reasons: the zero ripple condition (14) cannot be achieved due to integer number of turns and difficulty to set the gap thickness to the exact value required, and a real converter does not apply the same voltage to both inductor windings due to a non-zero voltage ripple on capacitors, DC voltage drop on inductors, switching noise and so on. As a consequence, the actual input current ripple depends also on the leakage inductance $\mathrm{L}_{\mathrm{d} 1}$ on the primary side.

As far as the design of the coupled inductors is concerned, there are three constraints that must be satisfied:

1) zero current ripple condition (14);

2) inductance $L_{2}$ must have the desired value imposed by the power stage design; in fact the equivalent inductance $\mathrm{L}_{\mathrm{e}}$ as defined in (11), coincides with $\mathrm{L}_{2 \mathrm{eq}}=\mathrm{L}_{2}$ since $\mathrm{L}_{1 \text { eq }}$ tends to infinity (see (16));

3 ) core saturation must be avoided.

For a detailed design procedure see [6].

\section{AUXILIARY CIRCUIT FOR SOFT-SWITCHING}

In order to reduce the electromagnetic noise generated during commutations a suitable auxiliary circuit was used, which allows soft transitions for all switches and diodes. The auxiliary circuit, composed by components $S_{\mathrm{r}}, \mathrm{D}_{\mathrm{r} 1}$, $\mathrm{D}_{\mathrm{r} 2}, \mathrm{C}_{\mathrm{r}}$ and $\mathrm{L}_{\mathrm{r}}$, is shown in the equivalent scheme of Fig. 5 in which $\mathrm{I}_{\mathrm{O}}$ corresponds to the sum of the two inductor currents $\mathrm{i}_{1}+\mathrm{i}_{2}$ and $\mathrm{V}_{\mathrm{in}}$ represents the voltage across capacitor $C_{1}$ given by the first of (3). As described in [4], switch $\mathrm{S}_{\mathrm{r}}$ is activated prior the main switch turn-on in order to discharge the parasitic capacitance of the main devices. In this way, the main switch turns on at zero voltage and, above all, a soft turn-off of the freewheeling diode is achieved, so avoiding the losses due to its recovery time.

Its behavior can be better understood by looking at the main converter waveforms reported in Fig. 6. Let us consider, initially, $\mathrm{I}_{\mathrm{O}}$ and $\mathrm{V}_{\text {in }}$ constants. Before instant $\mathrm{t}_{0}$, diode $\mathrm{D}$ is conducting the current $\mathrm{I}_{\mathrm{O}}$. At $\mathrm{t}_{0}$ the auxiliary switch is turned on under zero current condition and the resonant current $\mathrm{I}_{\mathrm{Lr}}$ rises linearly until it reaches the value $\mathrm{I}_{\mathrm{O}}$. Then, diode $\mathrm{D}$ is turned off in soft manner and $\mathrm{L}_{\mathrm{r}}$ can resonate with parasitic capacitances $\mathrm{C}_{\mathrm{d}}$ and $\mathrm{C}_{\mathrm{s}}$. At time $\mathrm{t}_{2}$, the body diode of the main switch starts to conduct allowing the zero voltage turn on of $S_{1}$. When $S_{r}$ is turned off (instant $t_{3}$ ), $L_{r}$ resonates with $C_{r}$ charging it to $V_{\text {in }}$ through $D_{r 1}$. Note that the auxiliary switch is turned off at zero voltage due to the presence of $\mathrm{C}_{\mathrm{r}}$. At instant $\mathrm{t}_{4}, \mathrm{D}_{\mathrm{r} 2}$ starts conducting and $\mathrm{I}_{\mathrm{Lr}}$ decreases linearly to zero flowing through $\mathrm{S}_{1}$ and $\mathrm{D}_{\mathrm{r} 2}$.

When $S_{1}$ is turned off its voltage increases linearly due to the charge of $\mathrm{C}_{\mathrm{S}}$ and discharge of $\mathrm{C}_{\mathrm{d}}$ and $\mathrm{C}_{\mathrm{r}}$ until, at instant $\mathrm{t}_{7}$ the diode $\mathrm{D}$ starts conducting initiating the usual freewheeling period. Note that all devices commutations are soft, both at turn on and turn off.

This is only one of the two possible operation modes in which we have assumed that, at instant $t_{3}$, the energy stored in $\mathrm{L}_{\mathrm{r}}$ is able to completely charge $\mathrm{C}_{\mathrm{r}}$ to $\mathrm{V}_{\mathrm{in}}$, i.e.:

$$
\frac{1}{2} \mathrm{~L}_{\mathrm{r}}\left(\mathrm{I}_{\mathrm{o}}+\mathrm{V}_{\mathrm{in}} \sqrt{\frac{\mathrm{C}_{\mathrm{eq}}}{\mathrm{L}_{\mathrm{r}}}}\right)^{2}>\frac{1}{2} \mathrm{C}_{\mathrm{r}} \mathrm{V}_{\text {in }}^{2}
$$

The other operation mode will be not considered here because it turns out to be less convenient then the first one. For more information see [4]. 


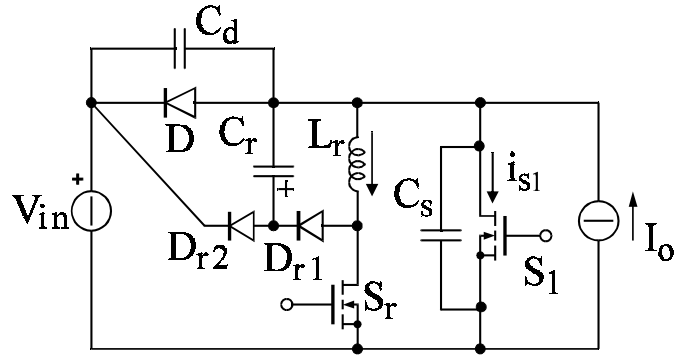

Fig 5 - Simplified schematics for analysis of the auxiliary circuit

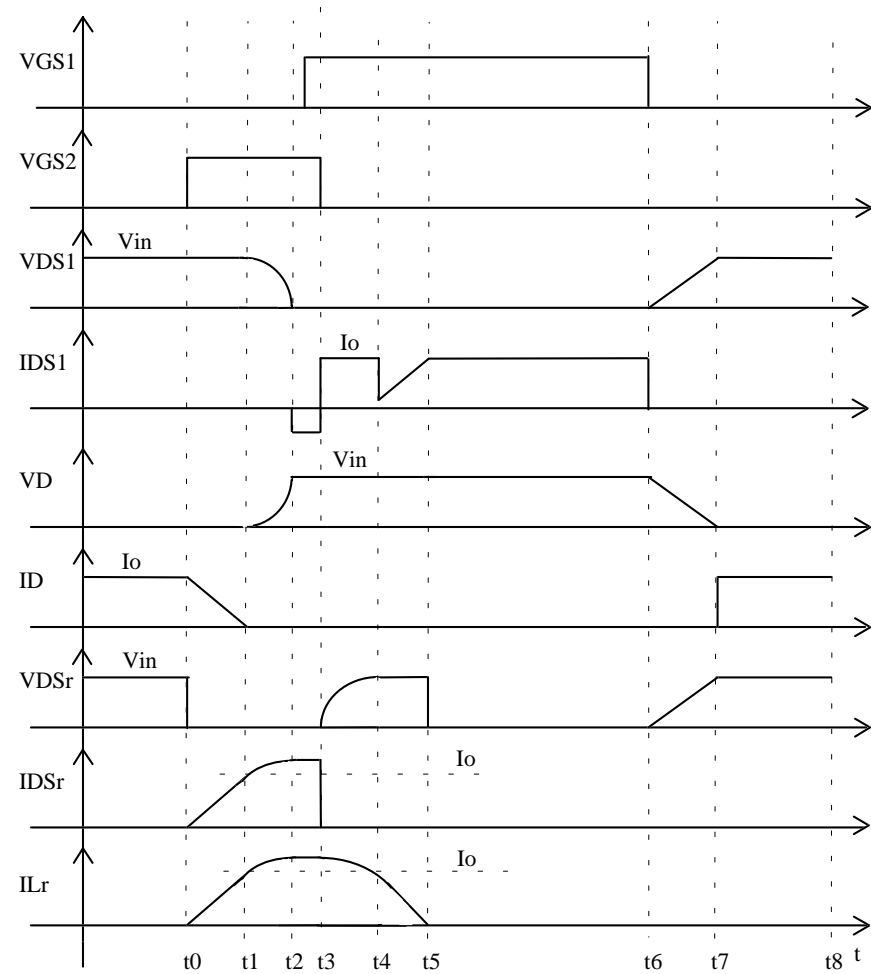

Fig. 6 - Main waveforms of the simplified circuit of Fig. 5b in a switching period

\section{AUXILIARY CIRCUIT DESIGN}

The presence of the auxiliary circuit limits the available duty-cycle. In order to estimate these limits we define an effective off time as [4]:

$\mathrm{t}_{\text {offe }}=\frac{1}{\mathrm{~V}_{\text {in }}} \int_{0}^{\mathrm{T}_{\mathrm{s}}} \mathrm{v}_{\mathrm{DS} 1} \mathrm{dt}$

Of course, such definition gives the usual off time in the case of hard switching converters in which $v_{D S}$ is a square wave. According to (18), the equivalent duty-cycle is then given by:

$\delta_{\mathrm{e}}=\frac{\mathrm{t}_{\text {one }}}{\mathrm{T}_{\mathrm{s}}}=\frac{\mathrm{T}_{\mathrm{s}}-\mathrm{t}_{\text {offe }}}{\mathrm{T}_{\mathrm{s}}}$

From the analysis of the waveforms of Fig. 6 the minimum value of the equivalent off time, which limits the maximum duty-cycle achievable, is:

$\mathrm{t}_{\text {offe min }}=\frac{\mathrm{I}_{\mathrm{o}} \mathrm{L}_{\mathrm{r}}}{\mathrm{V}_{\text {in }}}+\sqrt{\mathrm{L}_{\mathrm{r}} \mathrm{C}_{\text {eq }}}+\frac{\mathrm{V}_{\text {in }}}{2 \mathrm{I}_{\mathrm{o}}}\left(\mathrm{C}_{\text {eq }}+\mathrm{C}_{\mathrm{r}}\right)$ where $\mathrm{C}_{\mathrm{eq}}=\mathrm{C}_{\mathrm{d}}+\mathrm{C}_{\mathrm{s}}$. In the same manner the minimum switch on time can be derived as:

$\mathrm{t}_{\text {one min }}=\left(\frac{\pi}{2}-1\right) \sqrt{\mathrm{L}_{\mathrm{r}} \mathrm{C}_{\mathrm{eq}}}+\frac{\pi}{2} \sqrt{\mathrm{L}_{\mathrm{r}} \mathrm{C}_{\mathrm{r}}}+\frac{\mathrm{V}_{\text {in }}}{2 \mathrm{I}_{\mathrm{o}}}\left(\mathrm{C}_{\mathrm{eq}}+\mathrm{C}_{\mathrm{r}}\right)$

Now, we have to take into account that quantities $\mathrm{I}_{\mathrm{O}}$ and $\mathrm{V}_{\text {in }}$ in the implementation of Fig. 1 are not constant. In particular, neglecting the high frequency voltage ripple across $C_{1}$, voltage $V_{i n}$ is equal to $v_{g}(\theta)$ while, $I_{0}$ is equal to the load current $i_{\mathrm{L}}(\theta)$ (the low frequency current in $\mathrm{C}_{2}$ is negligible) given by:

$\overline{\mathrm{i}}_{\mathrm{L}}(\theta)=\frac{\overline{\mathrm{v}}_{\mathrm{L}}(\theta)}{\mathrm{R}_{\mathrm{L}}}$

Thus, since in (20) and (21) always compares the ratio between the two quantities we can write:

$\frac{\mathrm{V}_{\text {in }}}{\mathrm{I}_{\mathrm{o}}}=\frac{\mathrm{v}_{\mathrm{g}}(\theta)}{\mathrm{i}_{\mathrm{L}}(\theta)}=\frac{\mathrm{R}_{\mathrm{L}}}{\mathrm{M}\left(\delta_{\mathrm{e}}\right)}$

Thus specifying the maximum and minimum dutycycles from $(3,17,19-22)$ the values of the auxiliary circuit parameters $\mathrm{L}_{\mathrm{r}}, \mathrm{C}_{\mathrm{r}}$ and $\mathrm{C}_{\mathrm{eq}}$ can be derived, and the current and voltage stresses of these components can be calculated [4]. It is worthy to note instead that current and voltage stresses of the main devices remain the same as the hard-switching solution.

Note that, in this application, the limitation on the maximum duty-cycle achievable does not cause particular problems. In fact, the maximum power transfer can be anyway achieved by keeping the main switch always closed and thus avoiding the commutation losses at maximum power.

\section{EXPERIMENTAL RESULTS}

A prototype was designed and built with the following specifications: $\mathrm{V}_{\mathrm{i}}=220 \mathrm{~V}_{\mathrm{RMS}} ; \mathrm{P}_{\mathrm{L}}=1 \mathrm{~kW} ; \mathrm{f}_{\mathrm{S}}=25 \mathrm{kHz}$.

The converter parameter values are listed in Table $\mathrm{I}$ in which the value of $\mathrm{L}_{1}$ refers to the converter without magnetic coupling.

Fig. 10 shows the measured input current with and without magnetic coupling. The measurement was taken at a conversion ratio value which maximizes the current ripple: by comparison the magnetic coupling reduces the current ripple by a factor of six.

Table I - Converter parameters

\begin{tabular}{||c|c|c|c||}
\hline $\mathrm{L}_{1}=400 \mu \mathrm{H}$ & $\mathrm{L}_{2}=160 \mu \mathrm{H}$ & $\mathrm{C}_{1}=2 \mu \mathrm{F}$ & $\mathrm{C}_{2}=1 \mu \mathrm{F}$ \\
\hline $\mathrm{C}_{\mathrm{r}}=15 \mathrm{nF}$ & $\mathrm{L}_{\mathrm{r}}=31 \mu \mathrm{H}$ & $\mathrm{C}_{\mathrm{eq}}=7.5 \mathrm{nF}$ & $\mathrm{R}_{\mathrm{L}}=48 \Omega$ \\
\hline
\end{tabular}




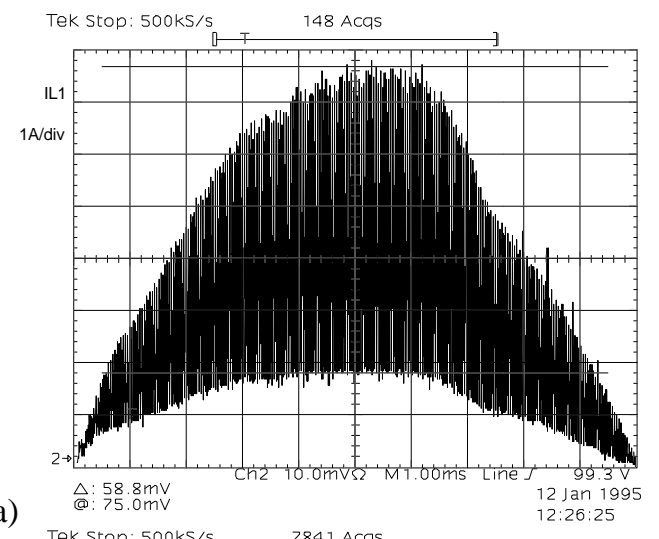

a)

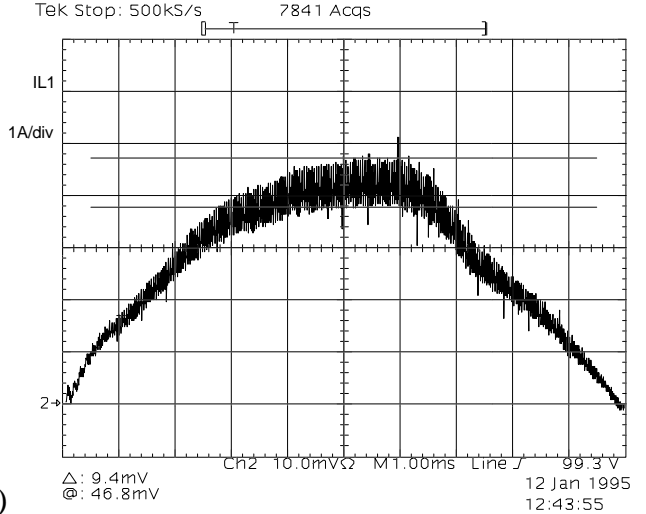

b)

Fig. 10 - Input current waveform at $\mathrm{V}_{\mathrm{i}}=220 \mathrm{~V}_{\mathrm{RMS}}$ and $\mathrm{I}_{\mathrm{i}}=3 \mathrm{~A}_{\mathrm{RMS}}$

a) without magnetic coupling; b) with magnetic coupling

The current total harmonic distortion is $5.8 \%$ while the line voltage distortion is $2.8 \%$. The measured power factor is 0.998 .

As far as the operation of the auxiliary circuit is concerned, Fig. 11 reports the comparison between the high frequency voltage and current waveforms of the main switch $S_{1}$ for the hard-switched and the soft-switched converter. The effects of the soft commutations are easily recognizable from Fig. 11b: at turn off the switch voltage stress is considerably reduced and, at turn on, no overlap between voltage and current occurs. Moreover, the big current spike due to the reverse recovery of diode D is eliminated.

The converter efficiency at the rated power remains approximately the same (about 95\%) with and without the zero-voltage transition network. However the main advantage of the soft transitions is the reduced EMI.

\section{CONCLUSIONS}

A high-quality rectifier for supplying resistive loads, featuring continuous power regulation, high power factor, low input current distortion and high efficiency is presented. It has continuous input current and same device stresses of a standard buck converter.

A suitable auxiliary circuit was used which allows soft commutations for all devices .

Converter design criteria were given and experimental tests done on a $1 \mathrm{~kW}$ prototype showed good agreement with the theoretical forecasts.

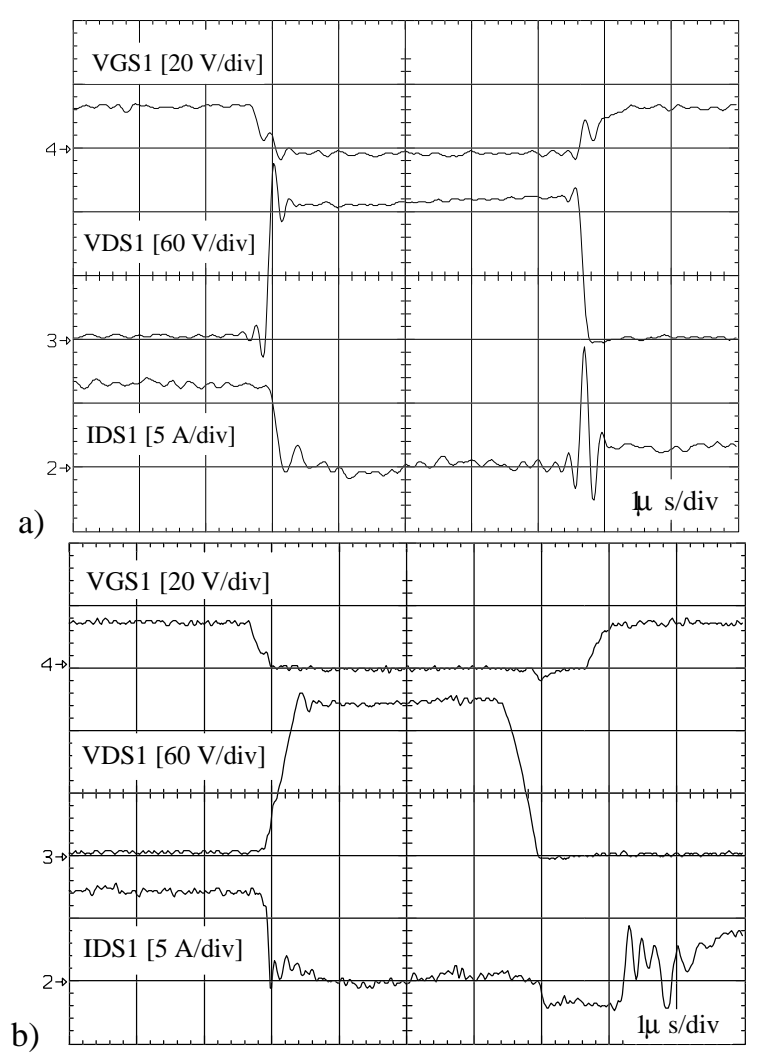

Fig. $11-\mathrm{S}_{1}$ waveforms in a switching period.

a) without auxiliary circuit; b) with auxiliary circuit

\section{ACKNOWLEDGMENTS}

The authors would like to thank Dr. M. Miolo, whose dedicated work made possible experimental tests.

Thanks are also due to Mr. R. Sartorello, who supervised experimental activities.

\section{REFERENCES}

[1] J. L. White, W. J. Muldoon, "Two-Inductor Boost and Buck Converters," IEEE Power Electronics Specialists' Conf. Rec., 1987, pp. 387-392.

[2] Z. Zhang, S. Cuk, "A High Efficiency $1.8 \mathrm{~kW}$ Battery Equalizer," IEEE Applied Power Electronic Conf. Proc., 1993, pp. 221-227.

[3] L. Rossetto, L. Malesani, G. Spiazzi, P. Tenti, J. A. Pomilio, C. Bocchiola, " High-Quality Rectifier for resistive Loads," Int. Conf. on Power Electronics, Drives and Energy Systems for Industrial Growth (PEDES), New dehli (India), January 1996, pp. 190196.

[4] S. B. Yaakov, G. Ivensky, O. Levitin and A. Treiner, "Optimization of the Auxiliary Switch Components in a Flying Capacitor ZVS PWM Converters," Applied Power Electronics Conf. Proc., 1995, pp.503509.

[5] R.D.Middlebrook and S.Cuk, Advances in SwitchedMode Power Conversion, vols. I and II, TESLAco, Pasadena, California, 1983.

[6] S.Cuk and Z.Zhang ,"Coupled-Inductor Analysis and Design", PESC Conf. Proc., 1986, pp. 655-665. 